\title{
Article
}

\section{Characteristics of Externally Venting Flames and Their Effect on the Façade: A Detailed Experimental Study}

Asimakopoulou, Eleni, Chotzoglou, Konstantinos, Kolaitis, Dionysios and Founti, Maria

Available at http://clok.uclan.ac.uk/31935/

Asimakopoulou, Eleni ORCID: 0000-0001-5644-1372, Chotzoglou, Konstantinos, Kolaitis, Dionysios and Founti, Maria (2016) Characteristics of Externally Venting Flames and Their Effect on the Façade: A Detailed

Experimental Study. Fire Technology, 52 . pp. 2043-2069. ISSN 0015-2684

It is advisable to refer to the publisher's version if you intend to cite from the work. http://dx.doi.org/10.1007/s10694-016-0575-5

For more information about UCLan's research in this area go to http://www.uclan.ac.uk/researchgroups/ and search for <name of research Group>.

For information about Research generally at UCLan please go to http://www.uclan.ac.uk/research/

All outputs in CLoK are protected by Intellectual Property Rights law, including Copyright law. Copyright, IPR and Moral Rights for the works on this site are retained by the individual authors and/or other copyright owners. Terms and conditions for use of this material are defined in the policies page.

\section{CLoK}

Central Lancashire online Knowledge www.clok.uclan.ac.uk

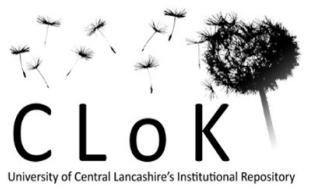




\title{
Characteristics of externally venting flames and their effect on the façade:
}

\section{A detailed experimental study}

\begin{abstract}
In a compartment fire, Externally Venting Flames (EVF) may significantly increase the risk of fire spreading to adjacent floors or buildings; EVF-induced risks are constantly growing due to the ever-increasing trend of using combustible materials in building facades. The main aim of this work is to investigate the fundamental physical phenomena associated with Externally Venting Flames (EVF) and the factors influencing their dynamic development. In this context, a series of fire tests is conducted in a medium-scale compartment-façade configuration; an n-hexane liquid pool fire is employed, aiming to realistically simulate an "expendable" fire source. A parametric study is performed by varying the fire load density $\left(127.75,255.5\right.$ and $\left.511 \mathrm{MJ} / \mathrm{m}^{2}\right)$ and opening factor $\left(0.071\right.$ and $\left.0.033 \mathrm{~m}^{3 / 2}\right)$. Emphasis is given to characterization of the thermal field developing adjacent to the façade wall. Experimental results suggest that the three characteristic EVF phases, namely "internal flaming", "intermittent flame ejection" and "consistent external flaming", are mainly affected by the opening dimensions, whereas the fuel load has a notable impact on the fuel consumption rate and heat flux to the façade. Fuel consumption rates were found to increase with increasing fire load and opening area, whereas the global equivalence ratio increases with decreasing opening factor. The obtained extensive set of experimental data can be used to validate CFD fire models as well as to evaluate the accuracy of available fire design correlations.
\end{abstract}

Keywords: Externally Venting Flames, façade, under-ventilated compartment fire, thermal effects on façade, heat flux, flame dimensions, fire plume, fire load, opening factor.

\section{Introduction}

In a fully developed, under-ventilated compartment fire, flames may spill out of external openings (e.g. windows) in case the glazing fails. It is well established that Externally Venting Flames (EVF) significantly increase the risk of fire spreading to higher floors or adjacent buildings. New facade design concepts and construction materials challenge the established fire safety design codes [1]. Due to the ever-stricter requirements for building 
energy performance, there is a growing trend of installing, usually flammable, thermal insulation materials on building façades. This energy saving practice is adversely affecting the building's fire safety characteristics related to EVF [2].

Although significant research has been conducted focusing on the impact of EVF on the façade and the parameters affecting its development, there are scarce reports focusing on the dynamic nature of EVF. Research on EVF during the past decades has been focused mainly on identifying the main physical parameters affecting the characteristics of the indoor fire and the subsequent EVF emerging outside the compartment. Results from the pioneering work of Yokoi [3], which have been further expanded by others [4-7], especially in terms of the EVF envelope shape and its impact on the façade, have been gradually incorporated in fire safety codes and design guidelines. The Eurocode design guidelines [8], currently implemented in the E.U., provide general principles and rules regarding the thermal and mechanical actions on structures exposed to fire; fire actions for designing load-bearing structures are prescribed in EN 1991, Part 1-2 (Eurocode 1) [8]. However, there is only a coincidental reference to risks associated with EVF (i.e. protection of steel and timber building elements); also fire spreading due to combustible façade materials is not directly addressed in the Eurocode guidelines.

\subsection{Physical Parameters Affecting the EVF}

EVF can be loosely described as a vertical rising turbulent jet of flames and hot combustion products ejecting through the opening of a compartment $[9,10]$. The EVF plume, commonly considered as fairly incompressible, is principally driven by thermal buoyancy; its trajectory is not entirely vertical, as demonstrated by Himoto et al. [11]. There is currently no consensus regarding the definition of the origin of the EVF, since the exit flow is usually a horizontally moving jet driven by buoyancy and momentum; this has been initially pointed out by Yokoi [3], who was the first to study plumes and flames venting out of windows, and more recently by $\mathrm{Hu}$ et al. [10] who investigated the EVF shape by employing a variety of characteristic length scales.

Research on medium-scale compartment-façade configurations [11, 12] has established the direct relation of the EVF envelope shape to the excess heat release rate and distance from the façade; new length scales to describe the EVF centerline distance from the facade have been recently proposed by Delichatsios et al. [12]. When EVF are established, it is not 
straightforward to characterise the combustion phenomena occurring at the exterior of the fire compartment $[3,12,13]$, especially in under-ventilated fire conditions where combustion cannot be completed inside the compartment [12]. In this case, an increasing quantity of the ejected flammable gases eventually burn when they are mixed with the oxygen-rich ambient air, resulting in a larger overall EVF envelope volume.

As it has been demonstrated in previous studies [14-16], the prevailing ventilation conditions and the fire load have a significant impact on fire development and the transition between over- and under-ventilated conditions. In order to establish a relationship between ventilation conditions inside the fire compartment and the fuel mass loss rate, the theoretical Global Equivalence Ratio (GER) value can be dynamically estimated using Equation (1), which is based on the methodology initially proposed by Kawagoe [17] and applied by Babrauskas [18]. The main parameters affecting GER are the fuel mass loss rate $\left(\dot{m}_{f u e l}\right)$, the upper gas layer temperature $\left(T_{g}\right)$, the ambient temperature $\left(T_{a}\right)$ and density $\left(\rho_{0}\right)$, the fuel stoichiometric ratio $(r)$, the opening's discharge coefficient $\left(C_{d}\right)$ and the opening height $\left(H_{v}\right)$ and width $\left(w_{v}\right)$.

$$
G E R(t)=\frac{\dot{m}_{f u e l}\left[1+\left(\frac{T_{g}(t)}{T_{\infty}}\right)^{1 / 3}\right]^{3 / 2}}{\frac{2}{3} H_{v}^{3 / 2} w_{v} C_{d} \sqrt{2 g} \rho_{0}\left(1-\frac{T_{\infty}}{T_{g}(t)}\right)^{1 / 2} r}
$$

The large impact of the fuel source location inside the compartment on important fire parameters, such as heat release rate (HRR), combustion efficiency and GER is well established [13]. More specifically, the distance between the fuel source and the opening is known to play a significant role in determining flow dynamics and the thermal and chemical environment within the compartment [13, 19-21]. Chamichine et al. [22], investigating the mass loss rate in a pool fire as a function of the distance between the fire source and the opening, have demonstrated that the maximum fuel mass loss rate is observed when the fire source is the farthest away from the opening. Recognizing the importance of the fire source location, it is pointed out that observations obtained in this work are limited to the specific configuration used, i.e. the fuel source is located at the centre of the compartment (cf. Section 2). 


\subsection{Dynamic Characteristics of EVF}

Although significant research has been conducted focusing on the impact of EVF on the façade and the parameters affecting its development $[5,12,14-16]$, there are scarce reports focusing on the dynamic (time transient) characteristics of EVF. Recently, Hu et al. [23] emphasized the dynamic behaviour of EVF and stressed the necessity to identify the conditions allowing EVF to be sustained at the exterior of the fire compartment.

One of the main parameters affecting the EVF dynamic characteristics is the fuel consumption rate [22]. However, in the majority of research work relevant to EVF, gas burners, providing steady-state conditions, have been used [5, 6, 9, 10, 12, 23]. Only a few studies [10, 14-16, 23] have employed a different approach, using more realistic, "expendable" fire sources, such as real furniture or liquid fuels. In these cases, it has been demonstrated that combustion is initially limited at the interior of the fire compartment (Internal Flaming phase, IF). As the flame front moves away from the fuel source, due to the gradual oxygen consumption inside the compartment, external flame jets and quick flashes appear at the exterior of the fire compartment (Intermittent Flame Ejection phase, IFE). Later on, the heat flux on the façade reaches a maximum value and is maintained almost constant for a prolonged time period, until the fire decay phase is reached. This time period corresponds essentially to the steady-state fully-developed fire stage [9]. Throughout this phase, EVF consistently cover the external region above the opening (Consistent External Flaming phase, CEF). Klopovic and Turan $[14,15]$ were the first to propose the CEF concept; in their work, compartment temperatures, mass loss rates, external temperatures and visual observations were used to determine CEF initiation. Currently, no specific criteria are available in the literature to estimate the initiation time and overall duration of the IFE and CEF phases.

The main aim of this work was to investigate the fundamental physical phenomena governing the dynamic characteristics of EVF. A series of compartment-façade fire tests were performed, employing a medium-scale model of the ISO 9705 room, equipped with an extended façade. An "expendable" fuel source, i.e. n-hexane liquid pool fire, was employed to effectively simulate realistic building fire conditions and a parametric study was performed by varying the total fire load and opening dimensions. The obtained experimental results were analysed aiming to investigate the dynamic nature of EVF; time averaged data were also 
employed to determine the overall EVF characteristics. Time averaging was performed for three characteristic time periods, namely the "Internal Flaming" (IF) phase, corresponding to the initial period when flames are mainly contained at the interior of the fire compartment, the "Intermittent Flame Ejection" (IFE) stage, when flame jets appear intermittently outside the compartment and the "Continuous External Flame" (CEF) stage that spans the time period when EVF are consistently ejected through the opening [14, 15, 23]. The time boundaries defining each stage were determined using video footage and mass loss rate measurements.

\section{Experimental Setup}

\subsection{Compartment Geometry}

A series of fire tests were conducted in a medium-scale compartment-façade configuration. The compartment was a $1 / 4$ scale model of the ISO 9705 standard compartment [24]. The internal compartment dimensions were $0.60 \mathrm{~m} \times 0.90 \mathrm{~m} \times 0.60 \mathrm{~m}$; the external façade wall measured $0.658 \mathrm{~m} \times 1.8 \mathrm{~m}$. A double layer of $12.5 \mathrm{~mm}$ thick fire-resistant gypsum plasterboards was used as lining material. The fire compartment opening, located at the centre of the north wall, measured either $0.20 \mathrm{~m} \times 0.50 \mathrm{~m}$ (door) or $0.20 \mathrm{~m} \times 0.30 \mathrm{~m}$ (window), depending on the test case. Construction gaps leading to the potential air leakage were plastered with ceramic fibre paste. A schematic drawing (side view and top section) of the experimental configuration, depicting the locations of the measuring devices, is shown in Figure 1.

\subsection{Expendable Fuel Source}

The majority of the actual furniture found in contemporary residential environments consists of hydrocarbon-based thermoplastic materials that melt and burn similar to liquid fuel pool fires. According to a recent study [19], the fire load owed to the upholstered furniture is the highest contributor in residential fires, increasing significantly the risk to the occupants of the building [19]. Gaseous burners are commonly used in relevant fire tests [5, 6, 10], aiming to provide a constant (steady-state conditions) fire source. However, in order to achieve more "realistic" fire conditions, an "expendable" fuel source (transient conditions) was used in this work, aiming to effectively simulate the typical HRR temporal evolution characteristics observed in actual residential fires. In this context, a characteristic hydrocarbon fuel, n- 
hexane, was used to formulate the fire load; n-hexane has been previously used in several compartment fire tests $[19,25,26]$. A stainless steel rectangular pan, measuring $0.25 \mathrm{~m} \times 0.25$ $\mathrm{m} \times 0.10 \mathrm{~m}$, was installed at the geometrical centre of the compartment's floor. The lower heating value of $\mathrm{n}$-hexane was estimated to be $43521 \pm 131 \mathrm{~kJ} / \mathrm{kg}$, using an isoperibolic oxygen bomb calorimeter [27]. The fuel mass was continuously monitored using a load cell, installed under the pan. The fuel pan size was selected in order to achieve under-ventilated conditions, thus facilitating the emergence of EVF.

\subsection{Sensors and Data Acquisition System}

The thermal behaviour of the EVF in the façade-compartment configuration was investigated using temperature and heat flux measurements. Ten K-type $1.5 \mathrm{~mm}$ diameter thermocouples, located at the front (CF) and rear (CB) corner of the compartment and four thermocouples vertically distributed at the centerline of the opening were used to determine the thermal field developing at the interior of the compartment (Figure 1). The recorded thermocouple data, obtained at the interior of the compartment, were corrected for radiation using a "postprocessing" methodology [28]. The "correction" methodology for gas temperature measurement uncertainties was used for gas temperatures at the interior of the fire compartment, aiming to mitigate the impact of errors associated with radiative heat transfer. The post-processed "correction" methodology is commonly applied for bare bead thermocouples, taking into account their geometrical characteristics. Special emphasis was given to the characterization of the EVF thermal impact on the façade wall. In this context, 14 thermocouples were placed at the exposed surface of the façade, in various heights above the opening; they were fixed in two characteristic positions across the width of the facade, one at the centre-line of the opening and the other corresponding to $25 \%$ of the total width of the façade $(x=164.5 \mathrm{~mm})$. Thermocouples were fixed to the facade surface following recommendations found in [29]. Each thermocouple was initially fixed onto the side of the façade and ran across its surface, until the intended location was reached; at this point, the tip of the thermocouple was bent, aiming to create an elastic force that allowed it to remain in contact with the façade surface throughout the test [30].

Aiming to characterize the thermal field of the EVF, 27 additional thermocouples were distributed among two thermocouple trees, obtaining measurements at various distances from the façade (cf. Figure 1). EVF may induce high fire plume velocities, thus increasing the risk 
of a "cantilevered" thermocouple to move. Therefore, one of the main design requirements for the temperature measurement system was to ensure that the spatial position of the thermocouple tip remained unaltered during the course of the test. Towards this end, $1.5 \mathrm{~mm}$ diameter thermocouples, providing increased stability and sturdiness, were selected. Prior to each fire test, each thermocouple was carefully positioned and aligned; post-test inspection of the measurement locations revealed that the vast majority of the thermocouple tips were not shifted during the test. In general, $1.5 \mathrm{~mm}$ diameter type $\mathrm{K}$ thermocouples are commonly used in similar large-scale compartment fire tests presented in the open literature $[14,15,31]$, since they offer a good compromise between a broad range of contradicting requirements, such as response time, flexibility, size, mechanical strength, stability and line resistance.

A water-cooled, $25 \mathrm{~mm}$ diameter, Schmidt-Boelter total heat flux sensor was placed at the centreline of the façade surface facing the EVF, $110 \mathrm{~mm}$ above the compartment's ceiling. To ensure consistency in the experimental results, all tests were conducted in a controlled laboratory environment in order to eliminate potential effects of weather conditions.

All thermocouple and heat flux measurements were recorded using a universal data logging interface designed in the Labview software; the selected sampling frequency was $1.0 \mathrm{~Hz}$. This sampling rate is commonly used in similar large-scale compartment fire tests $[14,15,19,32]$; it is also suggested in relevant guidelines for compartment fire tests [24, 33]. A thermal camera was positioned in front of the test compartment at a distance of $6.0 \mathrm{~m}$, to record additional information regarding the thermal response of the façade. The emissivity of the exposed façade surface has been taken into account; a value of 0.9 , typically used for gypsum plasterboards [34], has been employed. In addition, parameters such as distance from the façade, ambient temperature and relative humidity were also used to estimate the wall surface temperatures using the thermal camera software. In addition, two digital video cameras were positioned at two locations, opposite and at a right angle to the opening, to record the developing EVF envelope, at 30 frames per second. Time series of video frames were obtained and processed using an in-house developed Matlab code, aiming to determine the geometric characteristics of the EVF envelope [35]. Gas species concentrations were also obtained at a height of $1.65 \mathrm{~m}$, at the centreline of the façade; $\mathrm{CO}$ and $\mathrm{CO}_{2}$ concentrations were measured using infrared photometry, while $\mathrm{O}_{2}$ concentrations were obtained using an electrochemical cell. The gas sampling flow was adjusted to be $0.26 \mathrm{l} / \mathrm{min}$; before being analyzed, the exhaust gases passed through a filter to remove soot and tar residues. In all cases, data were acquired using a sampling interval of $1.0 \mathrm{~s}$. 


\subsection{Parametric Study}

A parametric study was performed, by varying the total fuel load (test cases D-1.00L, D2.35L and D-4.70L) and the opening dimensions (test case $\mathrm{W}-2.35 \mathrm{~L}$ ). The fire load used in test cases W-2.35L and D-2.35L was identical; the former case corresponds to a "door-type" opening, whereas the latter case refers to a "window-type" opening. A summary of the main operational parameters, i.e. initial fuel volume $\left(V_{f}\right)$ and mass $\left(m_{f}\right)$, fire load density $\left(Q^{\prime \prime}\right)$, opening height $\left(H_{v}\right)$ and width $\left(w_{v}\right)$, opening factor $\left(A_{v} H_{v}{ }^{1 / 2}\right)$, ambient temperature $\left(T_{\infty}\right)$ and relative humidity $\left(R H_{\infty}\right)$, total fire duration $\left(t_{d u r}\right)$, average total heat release rate $\left(\dot{Q}_{t o t}\right)$, maximum theoretical heat release rate at the interior of the compartment $\left(\dot{Q}_{i n, \max }\right)$ and average "excess" heat release rate $\left(\dot{Q}_{e x}\right)$ at the exterior of the compartment, for all the examined test

cases is given in Table 1 . The average heat release rate at the interior $\left(\dot{Q}_{i n, \max }\right)$ and the exterior ( $\left.\dot{Q}_{e x}\right)$ of the compartment were estimated using Equations (2) and (3), respectively [6]; the average total heat release rate $\left(\dot{Q}_{t o t}\right)$ was estimated using the mass loss rate measurements, by assuming a unity combustion efficiency. In under-ventilated compartment fires, the combustion efficiency value is generally less than 1.0; therefore, the actual "indoor" heat release rate is expected to be lower than the maximum theoretical value $\left(\dot{Q}_{i n, \max }\right)$, estimated using Equation (2).

$$
\begin{gathered}
\dot{Q}_{i n, \max }=1500 \frac{H_{v}}{2} w_{v} \sqrt{H_{v}} \\
\dot{Q}_{e x}=\dot{Q}_{t o t}-\dot{Q}_{i n, \max }
\end{gathered}
$$

The overall design of the medium-scale compartment-façade fire tests was based on the hypothesis that a full-scale physical phenomenon can be simulated in a reduced scale experiment provided that certain non-dimensional parameters are preserved. There are three methodologies widely used to determine the non-dimensional functionality, namely Simple Complete Physics, Partial Differential Equation (PDE) identification and Buckingham $\pi$ 
theorem [9]; the latter was employed in this work. In this work, the wall boundary thermal properties are not taken into account, since the wall boundaries are considered essentially adiabatic. The fire source for test case D-2.35L, which was used as a benchmark, was selected according to the typical fire load design suggested in Eurocode 1 [8] for office premises (511 $\left.\mathrm{MJ} / \mathrm{m}^{2}\right)$; the experimental fire load $\left(255.5 \mathrm{MJ} / \mathrm{m}^{2}\right)$ was determined using the $\Pi_{2}$ group, derived from the energy conservation equation. In addition, similarity in radiative heat transfer was ensured by preserving the $\Pi 7$ group [9].

\section{Results and Discussion}

\subsection{Repeatability Tests}

Three identical fire tests were performed to assess the experimental repeatability; the respective operational parameters are presented in Table 2. Average temperature profiles at the interior of the fire compartment and heat flux at the façade were selected to be used as "repeatability indicators". As demonstrated in Figure 2 the three fire tests exhibited good repeatability; the shaded region in Figure 2 (left) indicates the calculated instantaneous standard deviation of the gas temperature in the entire compartment. An approximate 5.12\% relative difference in average temperature at the interior of the fire compartment and $31.82 \%$ in heat flux at the façade was observed. Furthermore, by performing a one way statistical analysis of variances (ANOVA) [13] on the obtained experimental data, it was concluded that the mean values of the average compartment temperature and heat flux at the façade were not significantly different, using a significance level of 5\%. Average EVF temperature contours at the opening centreline plane perpendicular to the façade, shown in Figure 3, illustrate that the developing EVF exhibits fairly repeatable characteristics. The time duration of the three characteristic EVF stages (IF, IFE and CEF) were found to be similar in all test cases (Table 2).

\subsection{Fuel Consumption Rate and GER}

The fuel consumption rate in a compartment pool fire is influenced by a variety of parameters, such as ventilation, radiation from the surrounding walls and thermal characteristics of the exposed rim above the fuel $[2,13]$. These effects are demonstrated in Figure 4 (top), where measurements of the instantaneous fuel consumption rate for all the examined test cases are 
presented. A 5 point moving Savitzky-Golay average smoothing methodology has been used to determine the fuel consumption rate for each test case. The mass loss rate of the pool fire, measured in open air fire tests, is also depicted. As expected, due to thermal feedback phenomena inside the fire compartment, measured fuel consumption rates are significantly higher than the respective open air fuel consumption rate. The vertical lines shown in Figure 4, indicate the transition time from IF to IFE (dotted lines) and from IFE to CEF (dash-dot lines) stages; the respective values are given in Table 3 . Increasing the fuel load or the opening area results in shorter EVF ejection time (CEF phase initiation); this finding is corroborated by similar observations reported in the literature [21, 36]. Thermal effects play an important role to the temporal evolution of the mass loss rate [31]. Increasing the fire load results in more intense heat transfer phenomena, due to the higher gas temperatures achieved at the interior of the fire compartment. The enhanced heat transfer rates result in increasing mass loss rates with increasing fuel load (Figure 4, top left). In addition, as time advances, gradual lowering of the liquid fuel level results in a slight increase of the instantaneous combustion rate. In the strongly under-ventilated conditions developing in W-2.35L, an almost constant burning rate is established until the fire reaches its decay stage, after approximately $650 \mathrm{~s}$.

The size of the opening affects the oxygen concentration close to the pool fire and, therefore, the overall duration of the fire event (Figure 4, top right); the burning period in test case W$2.35 \mathrm{~L}$ is prolonged due to the decreased opening area. The decreased ventilation rate increases the mixing rate of combustion products and incoming air, resulting in the hot layer approaching the compartment floor. In this case, the cold ambient air stream entering the compartment is increasingly entrained into the hot gas products, due to buoyancy and shear mixing occurring near the opening; these phenomena lead to the reduction of oxygen feeding the flame $[31,37]$. As a result, the fuel consumption rate in test case $\mathrm{W}-2.35 \mathrm{~L}$ is reduced compared to test case D-2.35L.

The time history of the calculated GER (Equation 1) for each test case is depicted in Figure 4 (bottom). When the value of GER exceeds unity (stoichiometric conditions) the fire is considered to be "under-ventilated" (ventilation controlled), whereas when GER is lower than 1.0 the fire is assumed to be "well-ventilated" (fuel controlled). Test cases D-2.35L, D-4.70L and W-2.35L corresponded to under-ventilated fire conditions. In all test cases, the GER value is less than 1.0 during the initial fire development stage, when flames are mainly restricted at the interior of the fire compartment. In test case D-1.00L, well-ventilated fire 
conditions prevail for the entire duration of the experiment; this is owed to the low fire load used. In the majority of the investigated test cases, the IFE stage was found to occur when the GER value was between 0.2 and 0.5 , whereas CEF [16] conditions prevailed when the GER value exceeded 0.5. These remarks suggest that instantaneous GER values could serve as a criterion in order to distinguish each fire phase. However, due to the dependency of GER to the position of the fire source, these observations are considered to be valid only for the specific configuration investigated in the tests, i.e. when the fire source is located at the centre of the fire compartment. In addition, the aforementioned GER value limits seem to be invalid for the highest fire load case (D-4.70L); however, since only one fire test was performed at the highest fire load configuration, an additional series of repeatability tests should be performed for the observed behaviour to be generalised and included in the overall analysis.

\subsection{Indoor Thermal Field}

\subsubsection{Characterization of the Indoor Thermal Field}

The vertical distribution of the time-averaged gas temperatures inside the compartment is depicted in Figure 5 for two characteristic locations, one near the opening (CF) and the other near the back side of the compartment (CB) (cf. Figure 1). As expected, increasing the fire load results in higher gas temperatures. Significantly lower temperatures are observed in case D-1.00L, which corresponds to a low fire load and well-ventilated conditions. When the opening area is decreased (W-2.35L) lower temperatures are observed; in addition, temperature variations along the height of the compartment are more modest in test case W$2.35 \mathrm{~L}$.

Figure 6 illustrates the time evolution of the temperature in the upper gas layer formed inside the compartment. The gas temperature time profiles exhibit similar characteristics in all test cases; the three typical stages of fire growth phase, quasi-steady state phase (corresponding to fully-developed fire conditions) and decay phase, typically encountered in compartment fires, can be easily identified.

\subsubsection{Air Mass Flow Rate and Composition of Gaseous Products}

The air mass flow rate entering the compartment through the bottom part of the opening ( $\dot{m}_{\text {air }}$ ) can be estimated using Equation (4), as a function of the discharge coefficient $\left(C_{d}\right)$, the 
density of ambient air $\left(\rho_{0}\right)$ and of the hot combustion products inside the compartment $(\rho)$ and the opening width $\left(w_{v}\right)$ and height $\left(H_{v}\right)$ [38]. The calculated values, employing the instantaneous temperature measurements at the opening and the interior of the compartment, are depicted in Figure 7. The estimated values are compared to predictions using a widely used empirical correlation [13], Equation (5); good levels of agreement are observed after the completion of the initial fire growth stage. It is evident that decreasing the opening area results in significantly reduced air mass flow rates (cf. Figure 7, right).

$$
\begin{gathered}
\dot{m}_{\text {air }}=\frac{2}{3} C_{d} \sqrt{2 g \rho_{o}\left(\rho_{o}-\rho\right)} H_{v}{ }^{2 / 3} w_{v} \\
\dot{m}_{\text {air }}=0.5 A_{v} \sqrt{H_{v}}
\end{gathered}
$$

There are scarce literature reports on the effects of EVF on the composition of the gaseous products exiting the fire compartment. EVF-related research [39-41] focuses mainly on the physics of flame projection; the effect of EVF on species concentrations has not been sufficiently investigated. In the majority of compartment fire tests, oxygen and combustion product concentrations are measured near the fuel source $[42,43]$ or at a sampling position in the hood [44], aiming to determine the heat release rate. In this work, the gas composition of the EVF product was measured near the top edge of the façade; the obtained measurements are shown in Figure 8 for two characteristic test cases (D-2.35L and D-4.70L). The $\mathrm{O}_{2}$ volume fraction drops gradually during the initial IF and IFE phases and reaches its minimum value during the CEF phase. In general, $\mathrm{CO}$ concentrations are practically negligible during the IF and IFE phases, when the GER is less than 0.8. Initiation of the CEF phase, where GER may exceed 1.0 (under-ventilated fire conditions) results in an increase in CO production; CO concentrations reach their peak values when peak GER is observed. In agreement with Forell and Hosser's observations [45], the rapid reduction of $\mathrm{CO}$ measured at the exterior of the fire compartment at the end of the IF phase is a strong indication of EVF occurrence. In general, initiation of the CEF phase corresponds to a transition in strongly under-ventilated conditions (cf. Figure 4, bottom), where combustion efficiency deteriorates due to the insufficient availability of $\mathrm{O}_{2}$, resulting in an increasing production of intermediate combustion products, e.g. CO. Establishment of a constant EVF at the exterior of the fire compartment during the 
CEF period is mainly owed to the unburnt fuel and intermediate combustion products (e.g. $\mathrm{CO})$ exiting through the opening.

\subsection{Outdoor Thermal Field}

\subsubsection{Stages of EVF Evolution}

In all the examined test cases, the fire behaviour was characterized by three distinct phases (stages) [21] appearing in succession, typical for an under-ventilated compartment fire [6, 36] (cf. Section 1.2). Initially, during the IF stage, combustion is constrained at the interior of the compartment. Gradually, the flame front moves away from the fuel source, expanding horizontally towards the opening. At a certain time, external flame jets and quick flashes appear at the exterior of the compartment, signifying the initiation of the IFE stage. As time advances, the IFE phase is succeeded by the CEF stage $[14,15]$, which is characterized by the sustained external combustion of unburnt volatile gases. Throughout the latter phase, the EVF consistently covers the external region above the opening, resulting in peak heat flux values at the façade surface. The measured duration of the three characteristic EVF stages for all the examined test cases is given in Table 3. In general, the total duration of the IF stage tends to decrease with increasing fire load. No general trend can be observed for the IFE phase; the total duration of the CEF stage is increased with increasing fire load and decreasing opening factor. In the D-1.00L test case, the reduced fire load results in well-ventilated conditions, prevailing for the entire duration of the fire test; in this case, all characteristic EVF phases exhibit a similar duration.

The relative EVF stage duration, normalized by the total combustion time $\left(t / t_{\text {total }}\right)$ and the corresponding time-averaged fuel consumption rate $\left(\dot{m}_{\text {fuel }}\right)$, heat flux to the facade and GER values are depicted in Figure 9. Similar fuel consumption rates are observed during the IF stage for all test cases. With the exception of test case D-4.70L, fuel consumption rates remain practically constant also during the IFE phase. During the CEF stage, average fuel consumption rates are generally increased; however, the fuel consumption rate is decreased with decreasing opening area. In the case of well-ventilated conditions (D-1.00L), fuel consumption rates remained practically constant during all three phases.

Very low GER values characterise the IF stage in all test cases. During the IFE phase, GER values are generally increased, indicating the transition from well- to under-ventilated 
conditions. GER values are generally above unity (under-ventilated fire conditions) during the CEF stage. GER values tend to increase with decreased opening factor, since the reduced air mass flow rate entering through the opening results in increasingly poor ventilation conditions (cf. Figure 7, right).

During the IF phase, heat flux at the exposed surface of the façade is almost negligible; heat flux values are gradually increased, during the IFE and CEF stages. When under- ventilated fire conditions prevail, heat flux values can be significantly increased. The opening area does not seem to have a significant effect on heat flux values during the CEF phase.

\subsubsection{Thermal Characterization of the EVF}

The time-averaged temperature contour plots shown in Figures 10-13 assist in determining the spatial distribution of the EVF-induced thermal field developing outside the compartment. The duration of each EVF stage is different for every test case (cf. Table 3). Contour plots are presented for two characteristic time periods, the IF (Figures 10 and 12) and the CEF (Figures 11 and 13) stage. The depicted data were obtained by linear interpolation of the temperature measurements obtained at the exterior of the fire compartment. The presented values correspond to measurements obtained at two planes perpendicular to the façade (cf. Figure 1), one at the centreline (T1C) of the opening (Figures 10 and 11) and the other at the quarterwidth (T1M) distance of the façade surface (Figures 12 and 13). The extent of the opening in each test case is represented by a grey region at the bottom left corner of each graph.

During the IF phase (Figure 10), peak temperature values are observed at the vicinity of the opening; a large EVF envelope is developed in test case D-2.35L, whereas low EVF temperatures are observed at the centreline plane of test case D-4.70L. In general, maximum gas temperatures observed in the IF phase rarely exceed $280^{\circ} \mathrm{C}$. EVF temperatures during the CEF phase are practically similar in all test cases, with the exception of D-1.00L; peak temperatures up to $800^{\circ} \mathrm{C}$ can be observed at a distance of $0.15 \mathrm{~m}$ away from the façade (Figure 11). EVF temperatures gradually decrease with increasing height. The EVF shape depends on both the fire load and the opening geometry; the total volume of the EVF envelope is increased with increasing fire load and opening area. At the quarter width plane (Figures 12 and 13), lower temperature values indicate that the EVF is intensified near the centreline of the opening. When the fuel load is increased, the EVF becomes wider, whereas it narrows when the opening area is decreased. 


\subsection{Thermal Effects on the Façade}

The temporal evolution of the EVF temperature and heat flux on the façade is depicted in Figure 14. Initially, combustion is limited at the interior of the fire compartment (IF phase). As the flame front moves away from the fuel source and external flame jets and quick flashes appear at the exterior of the fire compartment (IFE phase), the heat flux increases. Consistently high heat flux values, close to the maximum observed levels for each test case, are observed during the CEF phase. Heat flux measurements suggest that the fuel load has a significant thermal impact on the façade. The dynamic behaviour of the EVF thermal field, as demonstrated by the temporal evolution of EVF temperatures at two characteristic heights, $0.71 \mathrm{~m}$ (corresponding to the height of the heat flux sensor) and $1.5 \mathrm{~m}$ above floor level (Figure 14, right), is critical as it directly affects the heat exposure of the façade. Temporal variations of the heat flux strongly depend on the EVF characteristics at the respective location; areas that are constantly exposed to flames receive more heat flux than those that are intermittently covered. As a result, the increased heat flux levels observed during the CEF phase for all test cases are associated with the prolonged exposure of the façade on the EVF plume that develops at the exterior of the compartment. Decreasing the opening area results in lower peak heat flux values, but a prolonged total combustion time, due to the strongly underventilated environment established in this case.

An overview of the thermal effect of EVF on the middle part of the façade is given in Figure 15 , where façade surface temperature measurements are depicted for test cases D-2.35L and $\mathrm{W}-2.35 \mathrm{~L}$; experimental data obtained by the thermal camera and the installed thermocouples are presented. The spatial distribution of the façade surface temperature using thermal infrared images is found to be in reasonable agreement with the corresponding thermocouple measurements. Surface temperatures measured using the thermal camera are slightly lower than the respective values obtained by thermocouples, especially at height levels lower than $1.1 \mathrm{~m}$. Discrepancies between thermal camera and thermocouple measurements may be attributed to various factors. For instance, when a thermocouple is used to measure a wall surface temperature in a fire environment, heat loss from the surface (e.g. façade wall) may be decreased due to the presence of the thermocouple since the latter "blocks" the incident thermal radiation [46]; other contributing factors include heat transfer between the bead and the surrounding bodies (gas, wall surfaces), conductive heat transfer along the thermocouple wire or the transient response of the bead [47]. 
On the other hand, uncertainties regarding the dynamic changes of the surface emissivity factor during the fire event may adversely affect measurements obtained with the thermal camera. It is evident that a larger opening (D-2.35L) results in a more severe thermal exposure of the façade (cf. Figure 14). Façade surface temperatures during the IF phase remained below $140^{\circ} \mathrm{C}$, for all test cases. When the EVF emerged from the opening, during the CEF stage, the increased radiation from the flames resulted in notably higher surface temperatures. In case of increased fuel load and decreased opening (cf. Figure 16) average temperatures reached up to $580^{\circ} \mathrm{C}$ on the areas directly above the lintel of the opening. In all test cases, surface temperatures decrease with increasing vertical distance from the opening.

\section{Conclusions}

A series of medium-scale fire tests was performed, employing a $1 / 4$ scale model of the ISO 9705 compartment, equipped with an extended façade. An "expendable" fuel source, i.e. nhexane liquid pool fire, was utilized to effectively simulate realistic building fire conditions. A parametric study was conducted by modifying the total fuel load and the opening dimensions; the fire load was kept constant when the opening area was modified. In the majority of the examined test cases, under-ventilated fire conditions were developed; a slightly over-ventilated fire was established only in the case of the lower fire load. Fuel consumption rates were found to increase with increasing fire load and opening area. The initial fuel load was found to have a significant impact on the heat flux to the façade. On the other hand, the size of the opening area was not found to significantly affect the heat flux to the façade; however, GER values were found to increase with decreasing opening factor.

Three distinct EVF phases were observed, namely the IF, IFE and CEF stage. During the IF phase, GER and heat flux values were relatively low as the fire was mainly limited to the interior of the compartment; well-ventilated conditions prevailed and GER values did not exceed 0.2. The duration of the IF phase decreased with increasing fire load and decreasing opening factor; increasing the fire load also resulted in enhanced fuel consumption rates and total volume of the EVF envelope. Gas sampling downstream the EVF plume provided the means to assess the EVF combustion efficiency. The rapid reduction of $\mathrm{CO}$ at the end of the IF phase proved to be a strong indication of EVF occurrence. Using data from video footage, it was observed that EVF emerged at an average GER value of 0.2-0.5. Throughout the IFE stage, gradual increase in the GER and heat flux values indicated the transition from well- to 
under-ventilated conditions; for GER values less than 0.6-0.8, almost negligible CO production was observed. During the CEF stage, the fire became substantially underventilated, resulting in increased volume of the EVF envelope, fuel consumption rate, GER values and heat flux at the façade. The duration of the CEF phase was significantly increased with decreasing opening area.

The extensive set of experimental data, obtained in both the interior and the exterior of the fire compartment, can be used to validate CFD models [48] or evaluate the accuracy of fire engineering design correlations currently available.

\section{Appendix. Estimation of Experimental Errors}

The ASME methodology [49] has been used to estimate the uncertainty of the measurements presented in this work. The total (expanded) measurement uncertainty $\left(U_{t}\right)$ is estimated using Equation (A.1), where $B_{t}$ is the root sum square of the elemental uncertainty estimated by statistical methods (e.g. systematic or bias uncertainties) and $S_{t}$ is the root sum square of the elemental uncertainty estimated using non-statistical methods (e.g. scientific judgment, manufacturer's specifications, calibration reports, random uncertainties). The expanded uncertainty is obtained by multiplying the combined standard uncertainty by a coverage factor $k$; in this work, a coverage factor value of $k=2$ was used, aiming to achieve a 95\% confidence interval $(2 \sigma)$ for the total uncertainty [50]. The values of the root sum square $\left(B_{t}\right.$ or $S_{t}$ ) of the various types of elemental uncertainties $\left(B_{i}\right.$ or $\left.S_{i}\right)$ are calculated using Equation (A.2).

$$
\begin{gathered}
U_{t}= \pm k\left(\left(B_{t} / 2\right) 2+S_{t}^{2}\right)^{1 / 2} \\
B_{t}=\left(B_{1}^{2}+B_{2}^{2}+B_{3}^{2}+\ldots\right)^{1 / 2}
\end{gathered}
$$

Gas and wall surface temperatures were measured using K-type thermocouples connected to the signal acquisition system via extension wires. Bare-bead thermocouples are assumed to have negligible statistical uncertainties $\left(B_{t}=0\right)$ [50]. In terms of the $S_{t}$ uncertainties, the Ktype thermocouples used in the tests exhibited a standard calibration uncertainty $\pm 2.2^{\circ} \mathrm{C}$ or 
$\pm 0.75 \%$ of the measurement reading (the largest value is taken into account) for a $99 \%$ confidence interval $(3 \sigma)$; in this work, the respective values of $\pm 1.5^{\circ} \mathrm{C}$ or $\pm 0.5 \%$ have been used to achieve a 95\% confidence interval $(2 \sigma)$. Another source of error in bare bead thermocouple measurements is radiative losses. Attempts of estimating the error due to radiation can be found in the literature [51]; in the current study radiative were assumed to be $0 \%$ to $-6 \%$. In addition, a $\pm 3 \%$ random error was introduced in the analysis.

Measurements using heat flux sensors are subjected to errors due to sensor properties, calibration traceability, quality assurance and measurement-related uncertainties. The initial calibration accuracy of the heat flux sensors used in the tests was $\pm 3 \%$. In addition to this error, the most significant error sources are non-linearity, convection and the radiative heat transfer balance. A $\pm 1 \%$ sensitivity error was employed, based on the assumption that the mean air speed was $0.5 \mathrm{~m} / \mathrm{s}$; also, a $\pm 6 \%$ convective error and a $\pm 3 \%$ random error were also taken into account.

In terms of the gas concentration measurements, the real-time gas analyser used in the tests exhibited an equipment uncertainty of $\pm 1 \%$. The calibration gases used for zero and span calibrations exhibited negligible uncertainties, as reported by the manufacturers. Zero and span calibrations performed prior to each experiment showed a systematic standard uncertainty of $\pm 1 \%$. Random and mixing/averaging errors due to the sampling lines, equal to $\pm 3 \%$ and $\pm 5 \%$, respectively, were the larger sources of uncertainty. Estimated values for all components of measurement uncertainty are tabulated in Table A1. Indicative values of the estimated experimental errors for the gas temperature inside and outside the fire compartment and the heat flux to the façade surface are presented in Figures 6 and 14.

\section{References}

[1] Nishio Y, Yoshioka H, Noguchi T, Kanematsu M, Ando T, Hase Y, Hayakawa (2015) Fire spread caused by combustible facades in Japan, Fire Technol 53:1-26. doi:10.1007/s10694-015-0535-5

[2] White N, Delichatsios M (2014) Fire hazards of exterior wall assemblies containing combustible components. Springer Briefs in Fire, Springer, New York

[3] Yokoi S (1960) Study on the prevention of fire spread caused by hot upward current. Building Research Institute, Report No 34, Tokyo, Japan. 
[4] Thomas IR, Moinuddin KA, Bennetts ID (2007) The effect of quantity and location on small enclosure fires. J Fire Prot Eng 17:85-102.

[5] Oleszkiewicz I (1989) Heat transfer from a window fire plume to a building façade. Reprinted from "Collected papers in heat transfer", HTD-Vol. 123, Editors: Marner WJ, Chen TC, Faghri M, Peterson GP, Kuehn TH, Pate MB, Mahajan RL and Lavine AS, Book No. H00526.

[6] Tang F, Hu LH, Delichatsios MA, Lu KH, Zhu W (2012) Experimental study on flame height and temperature profile of buoyant window spill plume from an under-ventilated compartment fire. Int J Heat Mass Tran 55:93-101.

[7] Oleszkiewicz I (1991) Vertical separation of windows using spandrel walls and horizontal projections. Fire Technol 4:334-340.

[8] Eurocode 1 (EN 1991-1-2) (2002) Actions on structures, Part 1-2 - General Actions Actions on Structures Exposed to Fire, Brussels

[9] Quintiere JG (2006) Fundamentals of Fire Phenomena. Wiley, West Sussex

[10] Hu L, Qiu Z, Lu K, Tang F (2015) Window ejected flame width and depth evolution along façade from under-ventilated enclosure fires. Fire Safety J 76:44-53.

[11] Himoto K, Tsuchihashi T, Tanaka Y, Tanaka T (2009) Modelling the trajectory of window flames with regard to flow attachment to the adjacent wall. Fire Safety J 44: 250-258.

[12] Delichatsios M, Lee Y, Tofilo P (2009) A new correlation for gas temperature inside a burning enclosure. Fire Safety J 44:1003-1009.

[13] Hurley MJ (2016) SFPE Handbook of fire protection engineering. $5^{\text {th }}$ Ed., SFPE, Quincy, Massachusetts

[14] Klopovic S, Turan OF (2001) A comprehensive study of externally venting flames, Part I: Experimental plume characteristics for through-draft and no through-draft ventilation conditions and repeatability. Fire Safety J 36:99-133.

[15] Klopovic S, Turan OF (2001) A comprehensive study of externally venting flames, Part II: Plume envelope and centre-line temperature comparisons, secondary fires, wind effects and smoke management system. Fire Safety J 36:135-172.

[16] Empis A (2010) Analysis of the compartment fire parameters influencing the heat flux incident on the structural façade. Ph.D. Thesis, University of Edinburgh, U.K. 
[17] Kawagoe K (1958) Fire Behaviour in Rooms. Report of the Building Research Institute of Japan, No 27.

[18] Babrauskas V (1976) Fire Endurance in a Building, Report No. UBC FRG-76-16. Berkley, U.S.A.

[19] Parkes AR (2009) The impact of size and location of pool fires on compartment fire behaviour. Ph.D. Thesis, University of Canterbury, New Zealand.

[20] Hwang C, Lock A, Bundy M, Johnsoon E and Ko GH (2011) Effects of fuel location and distribution on full-scale underventilated compartment fires, J Fire Sci 29: 21-52.

[21] Drysdale D (1998) An introduction to Fire Dynamics, $2^{\text {th }}$ Ed., John Wiley \& Sons, New York, U.S.A.

[22] Chamichine AV, Makhviladze GM, Oleszcak P and Yakush SE (2007) Flame exhaust from pool fires in a small scale compartment with a single opening, Proceedings of the 5th International Seminar on Fire and Explosion Hazards, Edinburgh, U.K., 23-27 April 2007.

[23] Hu L, Lu K, Delichatsios M, He L, Tang F (2012) An experimental investigation and statistical characterization of intermittent flame ejecting behaviour of enclosure fires with an opening. Combust Flame 159:1178-1184.

[24] ISO 9705 (1993) International Organization for Standardization, ISO 9705 Fire Tests: Full-Scale Room Test for Surface Products, Geneva

[25] Gottuk DT, Roby RJ, Peatross MJ and Beyler CL (1992) Carbon monoxide production in compartment fires, Journal Fire Prot Eng 4: 133-150.

[26] Audouin L, Such JM, Malet JC and Casselmam C (1997) A real scenario for a Ghosting Flame, Proc. 5th Int. Symposium on Fire Safety Science, 1997, 1261-1272.

[27] ASTM D240-14 (2014) Standard Test Method for Heat of Combustion of Liquid Hydrocarbon Fuels by Bomb Calorimeter, ASTM International, West Conshohocken, U.S.A.

[28] Kolaitis DI, Asimakopoulou EK, Founti MA (2014) Fire protection of light and massive timber elements using gypsum plasterboards and wood based panels: A large-scale compartment fire test. Constr Build Mater 73:163-170.

[29] Bentley R (1998) Handbook of temperature measurement. Springer-Verlag, Singapore [30] Jones JC (2014) Thermocouple usage in an irradiance experiment, J Fire Sci 32: 563 567. 
[31] Utiskul Y (2006) Theoretical and experimental study on fully-developed compartment fires. NIST GCR 07-907, National Institute of Standards and Technology, U.S.A.

[32] Hamins A, Maranghides A, McGrattan K, Johnsosson E, Ohlemiller T, Donnelly M, Yang J, Mulholland G, Prasad K, Kukuck S, Anleitner R, McAllister T (2005) Federal building and fire investigation of the World Trade Center disaster: Experiments and modelling of structural elements exposed to fire, NIST NCSTAR 1-5B, National Institute of Standards and Technology, U.S.A.

[33] ASTM E603-13 (2013), Standard Guide for Room Fire Experiments, ASTM International, West Conshohocken, U.S.A.

[34] Kolaitis DI, Founti MA (2013) Development of a solid reaction kinetics gypsum dehydration model appropriate for CFD simulation of gypsum plasterboard wall assemblies exposed to fire. Fire Safety J 58:151-159.

[35] Asimakopoulou EK, Kolaitis DI, Founti MA (2015) Evaluation of fire engineering design correlations for externally venting flames using a medium-scale compartment façade fire experiment. In: Proceedings of the $9^{\text {th }}$ Mediterranean Combustion Symposium, Rhodes, Greece, 7-11 June 2015.

[36] Gottuk DT, Roby RJ, Beyler CL (1992) A study of CO and smoke yields from compartment fires with external burning, $24^{\text {th }}$ Symposium (International) on Combustion, The Combustion Institute 1729-1735.

[37] Nasr A, Suard S, El-Rabii H, Gay L, Garo JP (2011) Fuel mass-loss rate determination in a confined and mechanically ventilated compartment fire using a global approach, Combust Sci Technol 183: 1342-1359.

[38] Makhviladze GM, Shamshin AV, Yakush SE, Zykov AP (2006) Experimental and numerical study of transient compartment fires. Combust Explo Shock 42:723-730.

[39] Law M (1978) Fire Safety of External Building Elements - The Design Approach. AISC Engineering Journal, $2^{\text {nd }}$ Quarter.

[40] Seigel LG (1969) The projection of flames from burning buildings. Fire Technol 5: 43-51.

[41] Thomas PH, Heselden AJM (1972) Fully developed fires in single compartments: a cooperative research programme of the Conseil Internationale du Batiment", Conseil Internationale du Batiment Report No 20, Fire Research Note No 923. 
[42] Thomas PH (1991) Fire, flames and dimensional analysis. Proceedings of the $3^{\text {rd }}$ International Symposium on Fire Safety Science, International Association for Fire Safety Science, 3-26.

[43] Beyler CL (1986) Fire Plumes and Ceiling Jets. Fire Safety J 11:53-75.

[44] Pitts WM (1997) An algorithm for estimation carbon monoxide formation in enclosure fires. Proceedings of the $5^{\text {th }}$ International Symposium on Fire Safety Science, International Association for Fire Safety Science, 535-546.

[45] Forell B, Hosser D (2007) The relationship between ventilation conditions and carbon monoxide source term in fully-developed compartment fires. In: Drysdale D et al. (ed) Proceedings of the $5^{\text {th }}$ International Seminar on Fire and Explosion Hazards, Edinburgh, UK, 23-27 April 2007, 825-835.

[46] Bentley RE (1998) Handbook of temperature measurement, Springer, Singapore.

[47] Saito K (1993) Study of fire induced flow along the vertical cornel wall. Part 2, final report. NIST GCR 93-628.

[48] Zhao G, Beji T, Merci B, Application of FDS to under-ventilated enclosure fires with external flaming, Fire Technol 52:1-26. doi:10.1007/s10694-015-0552-4.

[49] Nakos JT (2004) Uncertainty analysis of thermocouple measurements used in normal and abnormal thermal environment experiments at Sandia's radiant heat facility and Lurance Canyon burn site. Technical Report SAND2004-1023, Sandia National Laboratories, Albuquerque, U.S.A.

[50] Lock A, Bundy M, Johnsson EL, Hamins A, Ko GH, Hwang C, Fuss P, Harris R (2008) Experimental study of the effect of fuel type, fuel distribution and vent size on fullscale underventilated compartment fires in an ISO 9705 room, NIST Technical Note 1603.

[51] Ukleja S (2012) Production of smoke and carbon monoxide in under-ventilated enclosure fires, Ph.D. Thesis, Ulster University, U.K. 


\section{Nomenclature}

\begin{tabular}{lll}
\hline Symbol & Units & Description \\
\hline$A_{v} H_{v}{ }^{1 / 2}$ & $\left(\mathrm{~m}^{3 / 2}\right)$ & Opening factor \\
$C_{d}$ & $(-)$ & Opening discharge coefficient $(0.68)$ \\
$H_{v}$ & $(\mathrm{~m})$ & Opening height \\
$m_{f}$ & $(\mathrm{~kg})$ & Fuel mass \\
$\dot{m}_{\text {air }}$ & $(\mathrm{kg} / \mathrm{s})$ & Air supply rate into the fire compartment \\
$\dot{m}_{\text {fuel }}$ & $(\mathrm{kg} / \mathrm{s})$ & Fuel mass loss rate \\
$Q^{\prime \prime}$ & $\left(\mathrm{MJ} / \mathrm{m}^{2}\right)$ & Fire load density \\
$\dot{Q}_{t o t}$ & $(\mathrm{~kW})$ & Average heat release rate \\
$\dot{Q}_{e x}$ & $(\mathrm{~kW})$ & Excess heat release rate \\
$\dot{Q}_{i n, m a x}$ & $(\mathrm{~kW})$ & Heat release rate at the interior of the compartment \\
$R H_{\infty}$ & $(\%)$ & Relative humidity of ambient air \\
$R$ & $(-)$ & Fuel to air stoichiometric ratio \\
$T_{g}$ & $\left({ }^{\circ} \mathrm{C}\right)$ & Upper gas layer temperature \\
$T_{\infty}$ & $\left({ }^{\circ} \mathrm{C}\right)$ & Ambient air temperature \\
$t_{d u r}$ & $(\mathrm{~s})$ & Total fire duration \\
$V_{f}$ & $(\mathrm{lt})$ & Fuel volume \\
$w_{v}$ & $(\mathrm{~m})$ & Opening width \\
$\rho_{0}$ & $\left(\mathrm{~kg} / \mathrm{m}^{3}\right)$ & Ambient air density \\
$\rho$ & $\left(\mathrm{kg} / \mathrm{m}^{3}\right)$ & Density of the hot combustion products \\
\hline Acronyms & \\
\hline CEF & Consistent External Flaming \\
CB & Compartment Back \\
CF & Compartment Front \\
EVF & Externally Venting Flames \\
GER & Global Equivalence Ratio \\
IF & Internal Flaming \\
\hline
\end{tabular}




\section{Figure Captions}

Fig. 1 Schematic drawing of the experimental facility and sensor locations (W-2.35L)

Fig. 2 Time evolution and average gas temperatures inside the fire compartment (left) and heat flux at the façade (right) measurements obtained in the repeatability tests

Fig. 3 Time-averaged temperature contours at the centreline plane perpendicular to the façade, obtained in test cases D.1-2.35L and D.2-2.35L

Fig. 4 Measurements of instantaneous fuel mass consumption rate (top) and calculated GER (bottom); effect of fire load (left) and opening size (right)

Fig. 5 Time-averaged gas temperature at the interior of the compartment; effect of fire load (left) and opening size (right)

Fig. 6 Temporal evolution of upper gas layer temperature at the interior of the compartment; effect of fire load (left) and opening size (right)

Fig. 7 Temporal evolution of air mass flow rate entering into the compartment; effect of fire load (left) and opening size (right)

Fig. 8 Temporal evolution of $\mathrm{O}_{2}, \mathrm{CO}_{2}$ and $\mathrm{CO}$ volume concentrations measured at a height of $1.65 \mathrm{~m}$, at the centreline of the façade, for test cases D-4.70L (left) and D-2.35L (right)

Fig. 9 Averaged values of fuel consumption rate (top left), heat flux to the façade (top right), relative time duration (bottom left) and GER (bottom right) for each EVF stage 
Fig. 10 Time-averaged temperatures at the centre-line plane perpendicular to the façade during the IF phase

Fig. 11 Time-averaged temperatures at the centre-line plane perpendicular to the façade during the CEF phase

Fig. 12 Time-averaged temperatures at the quarter-width plane perpendicular to the façade during the IF phase

Fig. 13 Time-averaged temperatures at the quarter-width plane perpendicular to the façade during the CEF phase

Fig. 14 Temporal evolution of heat flux on the façade (left) and EVF temperatures at a distance of $0.246 \mathrm{~m}$ from the façade (right)

Fig. 15 Façade surface temperature at the end of the fire test; data obtained by thermal camera and thermocouples for test cases D-2.35L (left) and W-2.35L (right)

Fig. 16 Time-averaged façade surface temperatures during the CEF phase (thermocouple data) 